\title{
Acquisition of a simple operant by pigeons, rats, and monkeys without experimenter assistance
}

\author{
LAURENCE MILLER and VALERIA MURPHY \\ Western Washington University, Bellingham, Washington 98225
}

\begin{abstract}
Naive monkeys, pigeons, and rats were given the opportunity to acquire a simple operant without experimenter assistance. The monkeys and pigeons were rewarded with food on a continuous reinforcement schedule for either pressing a lever or pecking a lighted or dark response key. All monkeys acquired the response rapidly, one pigeon keypecked at the lighted key, and only one more keypecked when the key was flashed on and off. When an autoshaping procedure was introduced, three of the remaining four birds acquired keypecking. The rats were presented with several situations: (1) each leverpress turned on a light; (2) each leverpress produced food, and free food was intermittently concurrently presented; (3) each leverpress produced a mild electric shock; (4) each leverpress produced a B-B. Leverpressing was rapidly acquired in the first two conditions but was not acquired in the last two conditions.
\end{abstract}

In instrumental or operant conditioning the emission of a response is followed by some consequence. Since there is no clear eliciting stimulus, before the frequency of the response can be increased the response must first occur. The several procedures available that can influence acquisition of an operant are described in Figure 1. These procedures are scaled along a continuum of the type and degree of experimenter assistance provided to the learner. With assistance, to a greater or lesser extent, the learner is provided help by the experimenter or teacher; with no assistance the learner is provided with no initial help or information, so that the behavior must be acquired solely on the learner's own; with counterassistance the information or help makes it more difficult to acquire the behavior than if that information or help had not been given.

Verbal instructions and modeling maximize the assistance provided. Verbal instructions describe the experimental contingencies by telling the subject to respond in a certain way. In modeling or imitation the subject is shown the appropriate behavior by a model or an instructor (Bandura, 1971).

With autoshaping and handshaping, assistance is provided but the final response is not initially made apparent. With handshaping the final behavior is successively approximated in small steps through differential reinforcement. With autoshaping the manipulandum upon which the operant is emitted is intermittently illuminated for several seconds; upon termination of the illumination, food is presented. After several such pairings, the subject responds on the manipulandum (Brown \& Jenkins, 1968).

We thank Merle Prim for use of the monkeys. Reprints may be obtained from Laurence Miller, Department of Psychology, Western Washington University, Bellingham, Washington 98225.
In magazine training the response is not reinforced or may not be permitted to occur. Rather, reinforcers are intermittently provided independently of behavior. Later the manipulandum is introduced and responses are reinforced. Magazine training familiarizes the subject with the type and location of the reinforcer and cues associated with delivery of the reinforcer. Ponicki (1974) found that following magazine training, all rats acquired leverpressing within the first session, earning 90 pellets within 17-34 min after exposure to the lever.

With preexposure to the environment, the subject is familiarized with the learning environment by being placed in it for a period of time. Brown and Rhue (Note 1) exposed rats to an operant chamber with the lever absent for $1-10 \mathrm{~h}$. When the rats were later tested for self-acquisition of food-reinforced leverpressing,

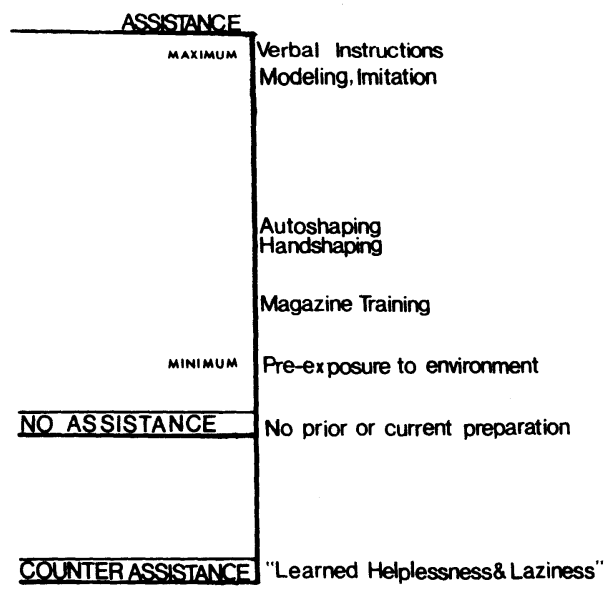

Figure 1. Three categories of conditions present during acquisition of an operant. Examples of each are on the right half of the vertical line. 
most rats reached a 50-leverpress criterion within a few minutes.

When no assistance is provided, the subject is placed directly in the learning situation and left entirely on its own to acquire the response. Rats will acquire leverpressing for food under this circumstance, with both simple (continuous reinforcement) and more complex (differential reinforcement of low rates, fixed and variable interval) schedules of reinforcement in effect (Kopp, Bourland, Tarte, \& Vernon, 1976; Linwick \& Miller, 1978; Miller, 1976; Miller \& Linwick, 1979).

In counterassistance a previously learned behavior retards or prevents acquisition of a subsequent behavior. In the "learned helplessness" and "learned laziness" procedures, response-independent shocks or food, respectively, retard acquisition of, respectively, an avoidance response or a response required to produce food (Engberg, Hansen, Welker, \& Thomas, 1973; Seligman, 1975).

The present study focused on the acquisition without any assistance of simple operants by rats and the other two most commonly used animal subjects, monkeys and pigeons. The following questions were examined: (1) Will rats rapidly acquire leverpressing even when simultaneously provided with response-independent food? (2) Will rats acquire leverpressing without assistance when the stimulus is something other than food? (Specifically, electric shock, B-Bs, and light onset were provided contingent upon each leverpress.) (3) Can monkeys and pigeons also rapidly acquire, respectively, leverpressing and keypecking without any assistance?

\section{METHOD}

\section{Subjects}

Five Macaca fascicularis monkeys from the Regional Primate Center, Seattle, Washington, were placed on a feeding schedule of $1 \mathrm{~h}$ of feeding after each test session per $24 \mathrm{~h}$. Subjects were allowed to adapt to the feeding schedule over a 10-day period prior to the beginning of the experiment. The monkeys were experimentally naive juvenile males, about 2 years old at the time of the experiment.

Six naive adult pigeons were deprived to $80 \%$ of their freefeeding weights over a 5 -day period prior to the experiment.

Thirty 6-month-old naive male rats were deprived to $80 \%$ of their free-feeding weights.

\section{Apparatus}

Monkeys. A black Plexiglas panel, $29.8 \times 24.8 \mathrm{~cm}$, was attached to the door of the monkeys' home cage. A metal lever, $2.5 \times 1.9 \times .6 \mathrm{~cm}$, and a metal tube, $.3 \mathrm{~cm}$ in diameter, extended from the panel about $2.6 \mathrm{~cm}$ into the cage. The lever was located in the top middle of the panel, and the tube was located about $5.1 \mathrm{~cm}$ below and to the left of the lever. Applesauce could be forced into the tube by a mechanical compressor. The panel was illuminated by a fluorescent tube fixed to the panel above the cage door opening.

Pigeons and rats. Standard Grason-Stadler pigeon and rat chambers were enclosed in sound-attenuating chests. One key and feeder tray were available to the pigeons, and a single lever and feeder tray were present in the rat chamber.

\section{Procedure}

Monkeys. The stimulus panel was presented to each monkey for seven daily sessions over a 7-day period. For Subjects 1-4 each leverpress produced a drop of applesauce reward on a continuous reinforcement schedule. Each animal was permitted to make about 200 responses per session. Subject 5 , the baseline control, did not receive applesauce for leverpressing. Four additional daily sessions were then presented, during which each leverpress was reinforced with an applesauce reward.

Pigeons. Subjects 1-6 were placed on a continuous reinforcement schedule for the keypeck response, with each peck permitting access to a hopper filled with grain for $4 \mathrm{sec}$. Fifteen 1-h sessions were presented. For Subjects 1,2 , and 5 , the key was continuously illuminated, and for Subjects 3, 4, and 6, the key remained dark throughout the session. Since, after the first 15 sessions, only Subject 5 acquired keypecking, an attempt was made to make the key a more salient stimulus. Subjects $1-4$ and 6 were presented with six $1-\mathrm{h}$ sessions on a continuous reinforcement schedule, during which the keylight briefly flashed at 4 -sec intervals for a .25 -sec duration. Since only Subject 6 acquired the keypeck with this procedure, Subjects $1-4$ were given six more sessions with an autoshaping procedure (Brown \& Jenkins, 1968), in order to determine if they would acquire keypecking. On the average of every $60 \mathrm{sec}$, the key was lighted for $8 \mathrm{sec}$. Upon termination of the light, subjects were given access to the feeder for $4 \mathrm{sec}$. A keypeck during the light produced food and turned off the light. Keypecks in the absence of the lighted key had no effect. Subjects were presented 60 light-food pairings each session.

Rats. For Subjects 1-6 each leverpress turned on a 15-W light bulb attached to the roof of the chamber directly above the lever. The light remained on for $5 \mathrm{sec}$. The chamber was otherwise completely dark. For Subjects 7-12 each leverpress produced a single 45-mg Noyes pellet. Concurrently with this schedule, a response-independent pellet was presented on the average of every $70 \mathrm{sec}$. Thus, subjects could obtain food by either leverpressing or not leverpressing. Eight 1 -h sessions were presented. For Subjects 13-18 each response produced a .16-mA electric shock of $.5 \mathrm{sec}$ duration. Pretesting with other rats indicated that this shock level was detected by the animal but did not cause it distress. Eight 1 -h sessions were presented.

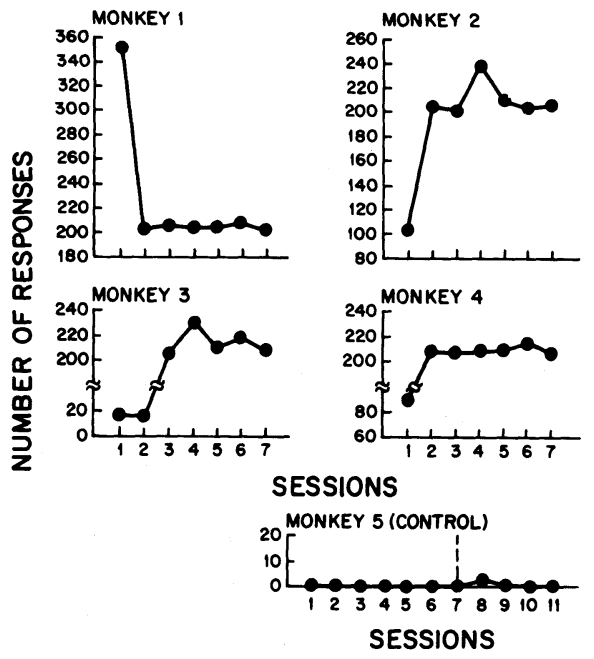

Figure 2. Number of responses emitted during each session. Applesauce was provided for each response to Monkeys 1-4 and to Monkey 5 during Sessions 8-11. Nothing was provided to Monkey 5 during Sessions 1-7. After Session 1 the number of applesauce presentations was limited to 200-240 to minimize digestive upsets. 
For Subjects 19-24 each leverpress produced a single coppercoated metal B-B. Eight 1-h sessions were presented. Subjects $25-$ 30 were controls for Subjects 1-24. For Subjects 25-26 each leverpress produced no consequence at all. For Subjects 27-28 each leverpress had no consequence but food pellets were presented independently of behavior. For Subjects 29-30 each leverpress discharged a B-B, but the B-B fell into a jar behind the response panel and was thus inaccessible to subjects. For all control animals, 15 1-h sessions were presented.

\section{RESULTS}

The data for the various subjects are presented in Figures 2-4. From Figure 2 it is apparent that all of the experimental monkeys acquired leverpressing within the first three sessions. The baseline control monkey emitted only a few responses when no applesauce was available and also did not acquire leverpressing when applesauce was made contingent upon responding.

Figure 3 reveals that Pigeon 5 acquired the keypeck response by the eighth session, with the light continually

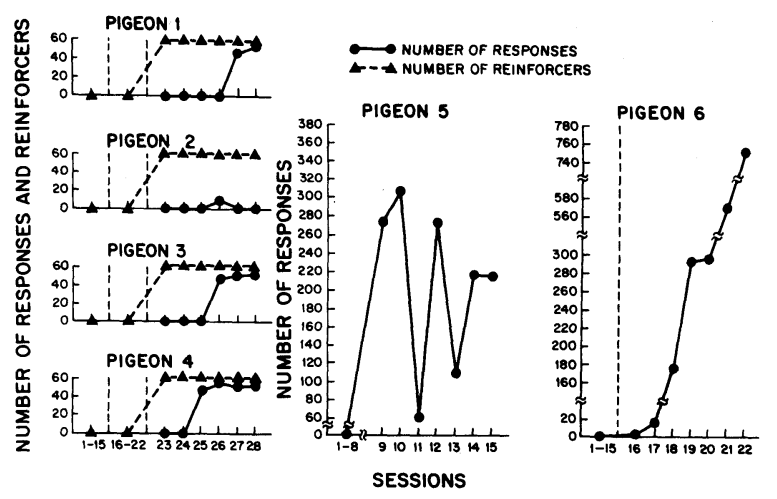

Figure 3. Number of responses emitted by each pigeon during the first 15 sessions, when each keypeck produced food. The key was either lighted (Subjects 1, 2, and 5) or unlighted (Subjects 3,4 , and 6). For Subjects $1-4$ and 6 the keylight was turned on and off during Sessions 16-22. For Subjects 14 an autoshaping procedure was used during Sessions 23-28. There were 60 response-independent food presentations during each of these sessions.

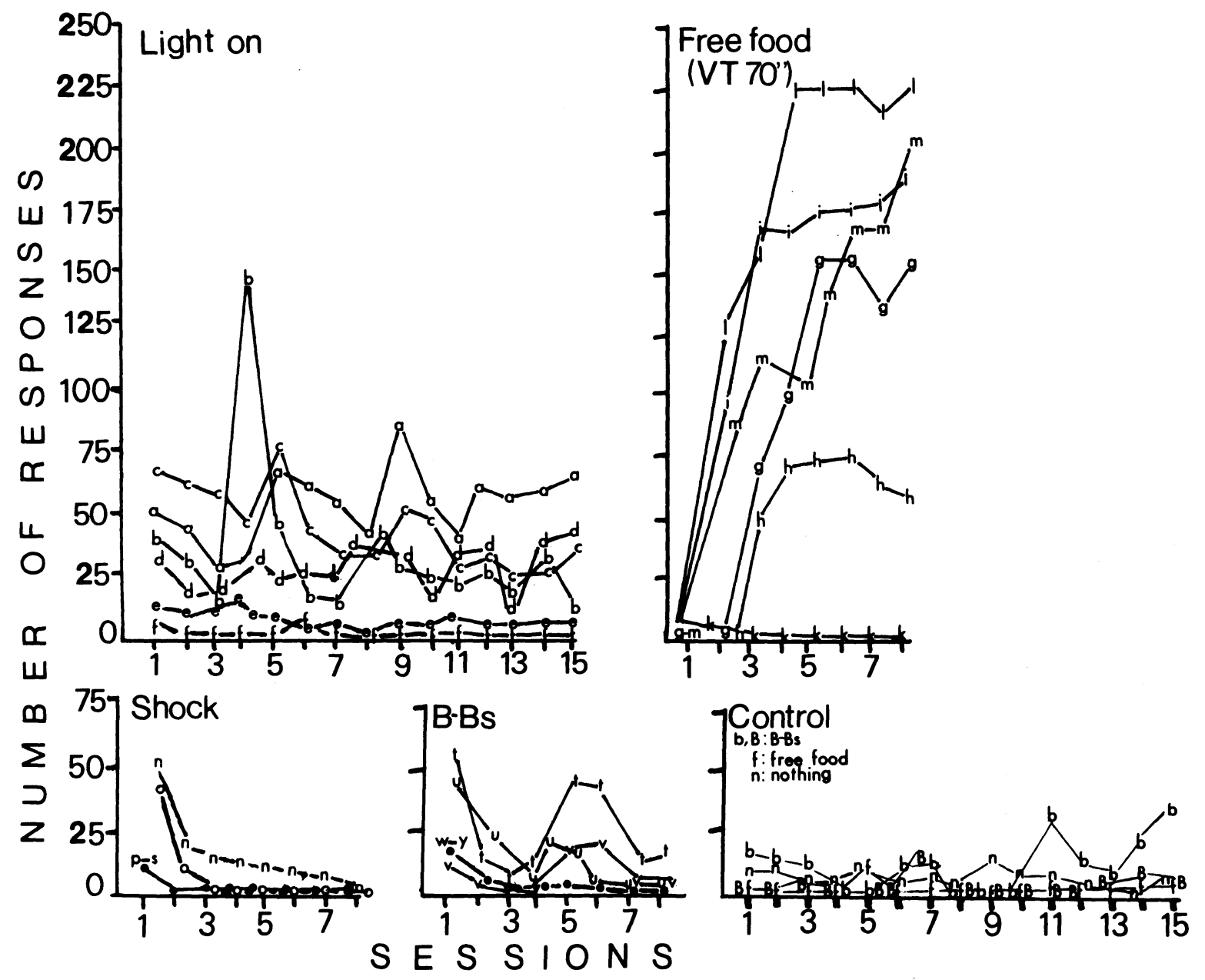

Figure 4. Number of responses emitted by rats each session when each leverpress was reinforced with various consequences: a 3-sec presentation of a light (top left panel); food, with response-independent food intermittently concurrently presented (top right); mild electric shock (bottom left); B-Bs (bottom center); control animals (lower right). Subjects are represented by letters rather than numbers to minimize crowding, and those rats with similar performance were averaged together (Subjects p-s in shock group, Subjects w-y in B-B group, subjects in the response-independent food (f), and nothing (n) control groups). 
on. Only Pigeon 6 acquired keypecking when the keylight was flashed at 4-sec intervals, during Sessions 17 and 18. Pigeons 1, 3, and 4 acquired keypecking during the autoshaping sessions, by Sessions 3-5. Pigeon 2 did not acquire keypecking with any of the procedures.

From Figure 4, four of six rats emitted a substantial and steady number of responses during each of the 15 sessions when light onset was the consequence of responding. Five of six rats acquired and maintained a high level of responding by the second or third session even though free food was at times concurrently presented. Very few responses occurred during the first one or two sessions, and subjects ate all of the pellets provided. This would indicate that behaviors other than leverpressing were conditioned by the free food. However, even though 85-125 free pellets were obtained during the first two or three sessions, all rats but one rapidly acquired leverpressing. The level of responding for this group was highest among the five groups. Electric shock failed to maintain responding. Responding appeared early with two animals but rapidly declined to near zero. B-Bs maintained erratic and inconsistent control; nearly all of the B-Bs obtained were taken from the food cup. The control animals exhibited a generally low level of responding, with only a few sessions marked by any degree of responding, mostly with one rat in the B-B group.

\section{DISCUSSION}

Adult monkeys rapidly acquired a continuously reinforced leverpressing response for food with no assistance. Rats achieved the same result even when concurrently presented with free food. Rats rapidly acquired leverpressing even when consequences other than food (light onset) were used, but this level of responding was much less than when barpressing produced food. Also, only certain stimuli were successful during acquisition and maintenance of leverpressing. Food and light onset were successful but mild electric shock and B-Bs were unsuccessful. Pigeons generally did not acquire keypecking for food without assistance. Only two of six birds acquired the response. Consistent with other reports, though, three of four remaining pigeons were readily autoshaped.

Monkeys, rats, and pigeons, as well as many other species, have been subjected to many of the training procedures involving assistance shown in Figure 1, and these procedures have produced rapid and effective conditioning. However, it is apparent that when no assistance is provided, pigeons do not generally acquire keypecking in comparison to rats and monkeys acquiring leverpressing. There are reports that dogs (Smith \& Smith, 1971) and cats (Chesler, 1969) also did not acquire leverpressing when no assistance was provided. However, because few training trials were given the dogs and a difficult task was provided the cats, it is not certain that these animals would not have acquired the response under more optimal conditions.

It seems, then, that for certain species it is equally easy to condition a simple operant whether assistance is or is not provided, but that for other species conditioning does not occur unless assistance is provided. Species differences and/or differences in the conditioning context would be the obvious sources of these differences.

\section{REFERENCE NOTE}

1.Brown, R. T., \& Rhue, J. W. Learned helplessness: You can lead $a$ rat to $a$ bar and make him press. Paper presented at the annual meeting of the Psychonomic Society, San Antonio, Texas, November 1978.

\section{REFERENCES}

Bandura, A. Psychological modeling. Chicago: Aldine-Atherton, 1971.

Brown, P. L., \& Jenkins, H. M. Auto-shaping of the pigeon's key peck. Journal of the Experimental Analysis of Behavior, $1968,11,1-8$.

Chesler, P. Acquisition of lever pressing with observation by kittens of mother and stranger models. Science, 1969, 166, 901-903.

Engberg, L. A., Hansen, G., Welker, R. L., \& Thomas, D. R. Acquisition of keypecking via autoshaping as a function of prior experience: "Learned laziness?". Science, 1973, 178, 1002-1004.

Kopp, B. G., Bourland, G., Tarte, R. D., \& Vernon, C. R. Acquisition of bar pressing in nondeprived rats. Psychological Record, 1976, 26, 49-54.

LINWICK, D. C., \& MILLER, L. Acquisition of leverpressing without experimenter assistance by rats on differential reinforcement of low rates schedules. Bulletin of the Psychonomic Society, 1978, 12, 193-195.

Miller, L. Acquisition of lever pressing by rats with and without magazine training. Psychological Record, 1976, 26, 255-259.

Miller, L., \& Linwick, D. C. Acquisition of leverpressing without assistance by rats maintained on interval and ratio schedules. Bulletin of the Psychonomic Society, 1979, 13, 103-104.

PoNICKI, E. A simple technique for auto-shaping lever-pressing by the rat within a single session. Psychological Record, 1974, 24, 119-122.

Seligman, M. E. P. Helplessness. San Francisco: Freeman, 1975. SMITH, S., \& SMITH, W., JR. A demonstration of auto-shaping with dogs. Psychological Record, 1971, 21, 377-379.

(Received for publication January $31,1979$. 